\title{
Analisis Kualitas Sinyal Wifi Pada Universitas Muslim Indonesia
}

\author{
Erick Irawadi Alwi* \\ *Program Studi Sistem Informasi, Fakultas Ilmu Komputer, Universitas Muslim Indonesia \\ erick.alwi@umi.ac.id
}

\begin{abstract}
Indonesian Muslim universities utilize WiFi networks as a facility to support the implementation of student and academic lecture activities within the scope of Indonesian Muslim universities. However, with the number of Indonesian Muslim University students around 17,000 people, internet access to the internet network has become slow. In addition, there are several faculties on several floors that do not get wifi signals or get weak signals so students cannot enjoy the internet network. Because it is necessary to measure the signal quality on wireless devices (AP) in each faculty in the scope of UMI with action research methods and analyze the signal quality so that it is known what factors can cause the wifi signal to sometimes be weak or not even get a signal at all
\end{abstract}

Keyword: Wireless, Internet, Signal Quality

\section{Introduction}

Perkembangan teknologi informasi dan komunikasi dalam era digital saat ini sangat pesat. Kebutuhan akan koneksi internet dalam hal ini jaringan wifi (wireless fidelity) atau hostpot sangat diminati oleh pengguna layanan internet, dikarenakan teknologi wifi relatif mudah untuk diimplementasikan pada lingkungan kerja maupun berkuliahan dan memberikan kebebasan kepada penggunanya untuk dapat mengakses kapan saja dan dimana saja melalui perangkat mobile seperti laptop dan smartphone.

Universitas muslim indonesia memanfaatkan jaringan wifi sebagai salah satu fasilitas untuk penunjang pelaksanaan kegiatan perkuliahan mahasiswa dan akademik di lingkup universitas muslim indonesia. Namun dengan banyaknya mahasiswa Universitas Muslim Indonesia yang kurang lebih sekitar 17.000 orang mengakibatkan akses internet ke jaringan internet menjadi lambat. Selain itu, ada beberapa fakultas di beberapa lantai tidak mendapat sinyal wifi atau mendapat sinyal yang lemah sehingga mahasiswa tidak dapat menikmati jaringan intenet dengan baik.

oleh karena itu peneliti akan mengukur kualitas sinyal pada perangkat wireless (AP) yang ada difakultas dilingkup Universitas Muslim Indonesia dan menganalisis kualitas sinyal tersbut sehingga diketahui faktorfaktor apa saja yang dapat menyebabkan sinyal wifi terkadang lemah atau bahkan tidak mendapat sinyal sama sekali. Mengukur kualitas sinyal dapat diketahui dengan melihat nilai parameter performa jaringan wifi yaitu,

1. Kuat Sinyal (Signal Strength)

Kualitas sinyal menentukan handal tidaknya suatu Wi-Fi, artinya semakin kuat sinyal maka semakin baik dan handal konektivitasnya. Kekuatan sinyal yang dipancarkan oleh perangkat Wi-Fi atau suatu Access Point sangat dipengaruhi oleh infrastruktur yang membangun access point tersebut[1].

Tabel 1. Skala Tingkatan Level Signal

\begin{tabular}{|c|c|c|}
\hline $\begin{array}{c}\text { Nilai Kuat Sinyal } \\
(\mathbf{d B m})\end{array}$ & Kategori & $\begin{array}{c}\text { Tingkat Kuat Sinyal } \\
\text { (Bar Sinyal) }\end{array}$ \\
\hline$>-60$ & Sangat baik & 5 \\
\hline$-60 \mathrm{~s} / \mathrm{d}-70$ & Baik & 4 \\
\hline$-71 \mathrm{~s} / \mathrm{d}-80$ & Cukup & 3 \\
\hline$-81 \mathrm{~s} / \mathrm{d}-90$ & Buruk & 2 \\
\hline$<-90$ & Sangat buruk & 1 \\
\hline
\end{tabular}

Sumber : Firdaus dkk, 2012 
Signal to Noise Ratio (SNR) adalah rasio perbandingan antara sinyal yang diterima dengan gangguan (derau) sekitar dengan satuan desibel (dB) [2]. Signal to Noise Ratio merupakan kunci penentu apakah jaringan wireless memiliki performa agus atau tidak.Semakin tinggi nilai , maka semakin bagus performa jaringan tersebut [3].

Tabel 2. Nilai SNR

\begin{tabular}{|c|c|c|}
\hline Nilai SNR & Kategori & Keterangan \\
\hline$>40 \mathrm{~dB}$ & Excellent & $\begin{array}{l}\text { Cepat terkoneksi, Troughput maksimal } \\
\text { dan stabil }\end{array}$ \\
\hline $25 \mathrm{~dB} \mathrm{~s} / \mathrm{d} 40 \mathrm{~dB}$ & Very good signal & Terkoneksi baik, Troughput maksimal \\
\hline $15 \mathrm{~dB} \mathrm{~s} / \mathrm{d} 25 \mathrm{~dB}$ & Low Signal & $\begin{array}{c}\text { Terkoneksi baik, throughput tidak } \\
\text { maksimal }\end{array}$ \\
\hline $10 \mathrm{~dB} \mathrm{~s} / \mathrm{d} 15 \mathrm{~dB}$ & Very low signal & $\begin{array}{l}\text { koneksi tidak terlalu stabil, throughput } \\
\text { rendah }\end{array}$ \\
\hline $5 \mathrm{~dB} \mathrm{~s} / \mathrm{d} 10 \mathrm{~dB}$ & No signal & $\begin{array}{l}\text { koneksi sangat tidak stabil, } \\
\text { throughput sangat rendah }\end{array}$ \\
\hline
\end{tabular}

Sumber: Onno Center, 2010

\section{Research Method}

Metodologi yang digunakan dalam penelitian ini adalah metode action research. Metode Action Research (penelitian tindakan) adalah merupakan cara ilmiah yang sistematis dan ersifat siklus digunakan untuk mengkaji situasi sosial, memahami permasalahan, an selanjutnya menemukan pengetahuan yang berupa tinakan untuk memperbaiki situasi tersebut [4]. Tahapan dalam metode action research ini adalah:

1. Melakukan diagnosa (Diagnosing)

Melakukan diagnosa dapat dilakukan dengan cara login atau masuk kedalam jaringan area cakupan hotspot Ukhuwahnet Universitas Muslim Indonesia. Diagnosa dilakukan dengan menggunakan tools Wifi SNR untuk dilakukan pengamatan.

\section{Membuat Rencana Tindakan (Action Planning)}

Rencana tindakan dengan melakukan konfigurasi pada tools Wifi SNR, pengaturan protokol dan berbagai pengaturan lainnya dilakukan dalam Wifi SNR yang selanjutnya dipakai dalam mengukur berbagai paramater kualitas sinyal hotspot wifi Ukhuwahnet Universitas Muslim Indonesia.

3. Melakukan Tindakan (Action Taking)

Tahapan melakukan tindakan adalah tahapan di mana semua paket data yang ditransmisikan melalui jaringan hotspot Universitas Muslim Indonesia, tindakan pengamatan arus jaringan dilakukan dengan mengamati Kuat Sinyal (Signal Strenght) dan Signal to Noise Ratio (SNR) untuk selanjutnya dianalisa.

\section{Melakukan evaluasi (Evaluating)}

Tahapan ini merupakan lanjutan dari hasil tindakan pada tahapan sebelumnya akan dianalisa dengan menghitung berbagai parameter Kualitas Sinyal. Hasil dari analisa jaringan hotspot Ukhuwanet universitas musli $\mathrm{m}$ indonesia selanjutnya akan dibandingkan dengan parameter kualitas sinyal untuk diketahui kategori kualitas sinyal pada hostpot wifi ukhuwahnet Universitas

\section{Pembelajaran (Learning)}

Analisa yang dilakukan pada tahap sebelumnya akan dilakukan penarikan kesimpulan tentang kualitas sinyal jaringan hotspot pada kamus 2 Universitas Muslim Indonesia, untuk selajutnya menjadi masukan bagi administrator jaringan yang bertanggung jawab terhadap kualitas jaringan.

\section{Result and Analysis}

3.1 Data Hasil Pengukuran 
Hasil pengukuran pada penelitian ini di dapat melalui test drive di lingkungan kampus 2 Universitas Muslim Indonesia, per lantai di 11 fakultas dalam waktu yang berbeda yaitu pada waktu pagi antara jam 08.00 WITA - 12.00 WITA dan siang jam 15.00 WITA -18..00 WITA.

Beberapa Hasil Pengamatan Signal Strength dan SNR menggunakan tool Wifi SNR :

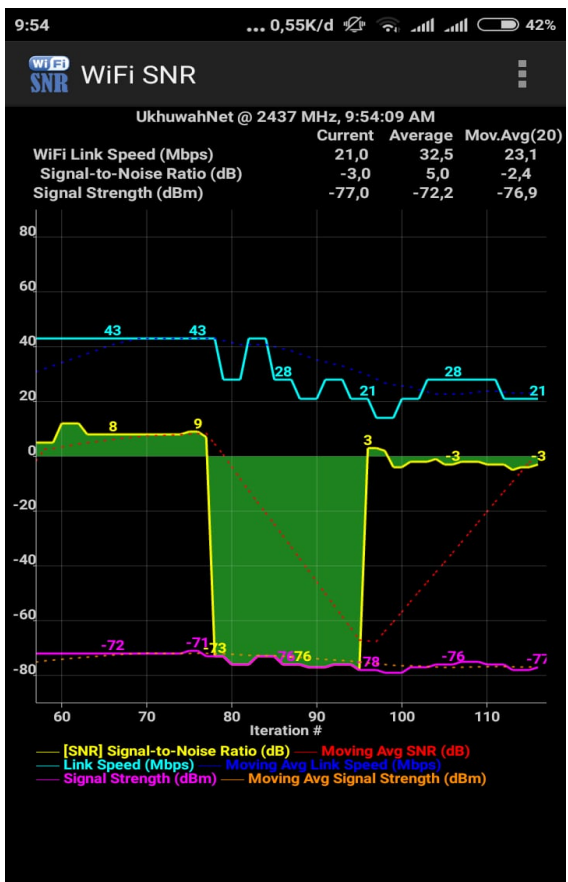

Gambar 1. Fakultas Teknologi Industri

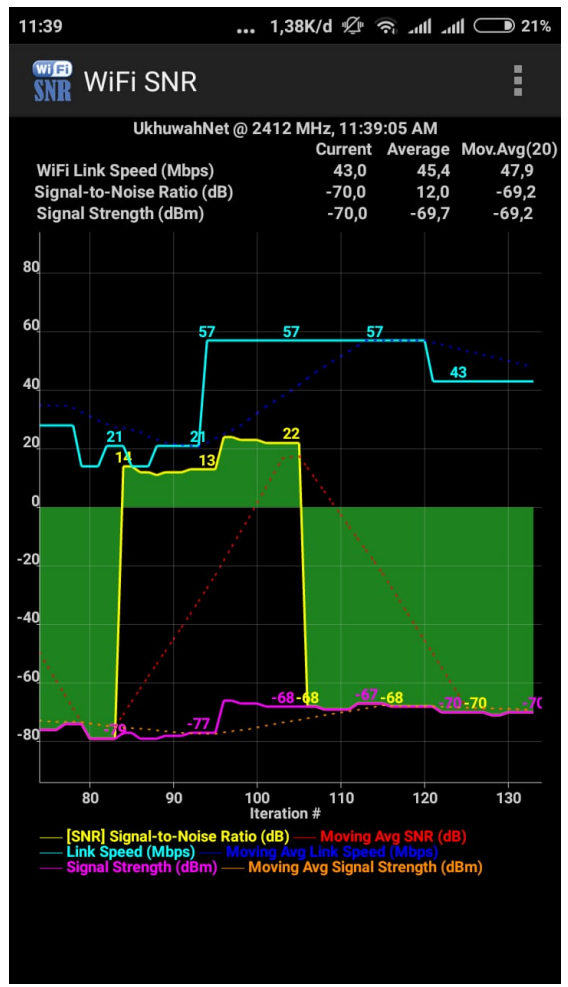

Gambar 2. Fakultas Ekonomi

Tabel 3. Hasil Signal strength dan SNR (pagi) 


\begin{tabular}{|c|c|c|c|c|}
\hline No & Fakultas & Lantai & Signal Strength (dBm) & Signal to Noise Ratio (dB) \\
\hline \multirow[t]{2}{*}{1} & Sastra & 1 & -61 & -2 \\
\hline & & 2 & -57 & 21 \\
\hline 2 & Hukum & 1 & -71 & 3 \\
\hline \multirow[t]{4}{*}{3} & Ilmu Komputer & 1 & -53 & 18 \\
\hline & & 2 & -70 & 6 \\
\hline & & 3 & -77 & -1 \\
\hline & & 4 & - & - \\
\hline \multirow[t]{5}{*}{4} & Agama & 1 & -60 & 6 \\
\hline & & 2 & -53 & 14 \\
\hline & & 3 & -75 & 8 \\
\hline & & 4 & - & - \\
\hline & & 5 & - & - \\
\hline \multirow[t]{4}{*}{5} & Pertanian & 1 & -69 & 13 \\
\hline & & 2 & -73 & -73 \\
\hline & & 3 & -53 & 20 \\
\hline & & 4 & -66 & -66 \\
\hline \multirow[t]{4}{*}{6} & Perikanan & 1 & -61 & 3 \\
\hline & & 2 & -68 & -6 \\
\hline & & 3 & -71 & -3 \\
\hline & & 4 & -79 & -79 \\
\hline \multirow[t]{5}{*}{7} & Kesehatan Masyarakat & 1 & -62 & 13 \\
\hline & & 2 & -48 & 17 \\
\hline & & 3 & -53 & 26 \\
\hline & & 4 & -76 & 9 \\
\hline & & 5 & - & - \\
\hline \multirow[t]{4}{*}{8} & Ekonomi dan Bisnis & 1 & -66 & 12 \\
\hline & & 2 & -65 & 8 \\
\hline & & 3 & -70 & -70 \\
\hline & & 4 & -67 & -67 \\
\hline \multirow[t]{3}{*}{9} & Teknik & 1 & -82 & -82 \\
\hline & & 2 & -62 & -62 \\
\hline & & 3 & -45 & -45 \\
\hline
\end{tabular}




\begin{tabular}{|c|l|c|c|c|}
\hline & & 4 & -72 & -72 \\
\hline 10 & Teknologi Industri & 1 & -48 & 19 \\
\hline & & 2 & -52 & -5 \\
\hline & & 3 & -66 & -3 \\
\hline 11 & Farmasi & 4 & -77 & -1 \\
\hline & & 1 & -85 & - \\
\hline & & 2 & - & - \\
\hline & & 3 & -81 & -4 \\
\hline & & 5 & -89 & \\
\hline
\end{tabular}

Tabel 4. Hasil Signal strength dan SNR (Sore)

\begin{tabular}{|c|c|c|c|c|}
\hline No & Fakultas & Lantai & Signal Strength (dBm) & Signal to Noise Ratio (dB) \\
\hline \multirow[t]{2}{*}{1} & Sastra & 1 & -73 & -22 \\
\hline & & 2 & -64 & 0 \\
\hline 2 & Hukum & 1 & -63 & 28 \\
\hline \multirow[t]{4}{*}{3} & Ilmu Komputer & 1 & -79 & -5 \\
\hline & & 2 & -44 & 28 \\
\hline & & 3 & - & - \\
\hline & & 4 & -84 & -23 \\
\hline \multirow[t]{5}{*}{4} & Agama & 1 & -58 & 8 \\
\hline & & 2 & -58 & -58 \\
\hline & & 3 & -79 & -79 \\
\hline & & 4 & - & - \\
\hline & & 5 & - & - \\
\hline \multirow[t]{4}{*}{5} & Pertanian & 1 & -72 & 20 \\
\hline & & 2 & -68 & 18 \\
\hline & & 3 & -74 & 10 \\
\hline & & 4 & -65 & 13 \\
\hline \multirow[t]{4}{*}{6} & Perikanan & 1 & -69 & 2 \\
\hline & & 2 & -49 & 31 \\
\hline & & 3 & -79 & -4 \\
\hline & & 4 & -83 & -3 \\
\hline
\end{tabular}




\begin{tabular}{|c|c|c|c|c|}
\hline \multirow[t]{2}{*}{7} & Kesehatan Masyarakat & 1 & -48 & 25 \\
\hline & & 2 & -64 & 26 \\
\hline & & 3 & -70 & -2 \\
\hline & & 4 & -71 & 4 \\
\hline & & 5 & -84 & 4 \\
\hline 8 & Ekonomi dan Bisnis & 1 & -71 & 3 \\
\hline & & 2 & -64 & 26 \\
\hline & & 3 & -56 & -56 \\
\hline & & 4 & 60 & 22 \\
\hline 9 & Teknik & 1 & -71 & 4 \\
\hline & & 2 & -66 & 4 \\
\hline & & 3 & -57 & 24 \\
\hline & & 4 & -67 & -67 \\
\hline \multirow[t]{4}{*}{10} & Teknologi Industri & 1 & -59 & 20 \\
\hline & & 2 & -55 & 34 \\
\hline & & 3 & -76 & 9 \\
\hline & & 4 & -82 & 0 \\
\hline \multirow[t]{5}{*}{11} & Farmasi & 1 & -75 & -1 \\
\hline & & 2 & 0 & 0 \\
\hline & & 3 & -89 & 0 \\
\hline & & 4 & -72 & 13 \\
\hline & & 5 & - & - \\
\hline
\end{tabular}

Tabel 5. Hasil rata-rata Signal strength dan SNR (pagi)

\begin{tabular}{|c|c|c|c|c|}
\hline No & Fakultas & Lantai & Signal Strength (dBm) & SNR (dB) \\
\hline 1 & Sastra & 1 & \multirow[b]{2}{*}{-59} & \multirow[b]{2}{*}{9.5} \\
\hline & & 2 & & \\
\hline 2 & Hukum & 1 & -71 & 3 \\
\hline 3 & Ilmu Komputer & 1 & \multirow{4}{*}{-66.66} & \multirow{4}{*}{7.66} \\
\hline & & 2 & & \\
\hline & & 3 & & \\
\hline & & 4 & & \\
\hline 4 & Agama & 1 & -62.66 & 9.33 \\
\hline
\end{tabular}




\begin{tabular}{|c|c|c|c|c|}
\hline & & 2 & & \\
\hline & & 3 & & \\
\hline & & 4 & & \\
\hline & & 5 & & \\
\hline \multirow[t]{4}{*}{5} & Pertanian & 1 & \multirow{4}{*}{-65.25} & \multirow{4}{*}{-26.5} \\
\hline & & 2 & & \\
\hline & & 3 & & \\
\hline & & 4 & & \\
\hline \multirow[t]{4}{*}{6} & Perikanan & 1 & \multirow{4}{*}{-69.75} & \multirow{4}{*}{-21.25} \\
\hline & & 2 & & \\
\hline & & 3 & & \\
\hline & & 4 & & \\
\hline \multirow[t]{5}{*}{7} & Kesehatan Masyarakat & 1 & \multirow{5}{*}{-59.75} & \multirow{5}{*}{16.25} \\
\hline & & 2 & & \\
\hline & & 3 & & \\
\hline & & 4 & & \\
\hline & & 5 & & \\
\hline 8 & Ekonomi dan Bisnis & 1 & \multirow{4}{*}{-67} & \multirow{4}{*}{-29.25} \\
\hline & & 2 & & \\
\hline & & 3 & & \\
\hline & & 4 & & \\
\hline \multirow[t]{4}{*}{9} & Teknik & 1 & \multirow{4}{*}{-65.25} & \multirow{4}{*}{-65.25} \\
\hline & & 2 & & \\
\hline & & 3 & & \\
\hline & & 4 & & \\
\hline \multirow[t]{4}{*}{10} & Teknologi Industri & 1 & \multirow{4}{*}{-60.75} & \multirow{4}{*}{10.25} \\
\hline & & 2 & & \\
\hline & & 3 & & \\
\hline & & 4 & & \\
\hline \multirow[t]{3}{*}{11} & Farmasi & 1 & \multirow{3}{*}{-85} & \multirow{3}{*}{0} \\
\hline & & 2 & & \\
\hline & & 3 & & \\
\hline
\end{tabular}




\begin{tabular}{|l|l|l|l|l|}
\hline & & 4 & & \\
\cline { 1 - 2 } & & 5 & & \\
\hline
\end{tabular}

Terlihat pada Tabel 5, ada beberapa fakultas signal strength dengan kategori baik di waktu pagi yaitu fakultas sastra, ilmu komputer, agama, pertanian, perikanan, ekonomi, teknik dan teknologi informasi. Fakultas yang termasuk kategori signal buruk hanya farmasi, kategori cukup untuk fakultas hukum dan fakultas kesehatan masyarakat dengan kategori sangat baik.

Tabel 6. Hasil rata-rata Signal Strength dan SNR (Sore)

\begin{tabular}{|c|c|c|c|c|}
\hline No & Fakultas & Lantai & Signal Strength (dBm) & SNR (dB) \\
\hline 1 & Sastra & 1 & \multirow{2}{*}{-68.5} & \multirow{2}{*}{-11} \\
\hline & & 2 & & \\
\hline 2 & Hukum & 1 & -63 & 28 \\
\hline 3 & Ilmu Komputer & 1 & \multirow{4}{*}{-69} & \multirow{4}{*}{0} \\
\hline & & 2 & & \\
\hline & & 3 & & \\
\hline & & 4 & & \\
\hline \multirow[t]{5}{*}{4} & Agama & 1 & \multirow{5}{*}{-65} & \multirow{5}{*}{-43} \\
\hline & & 2 & & \\
\hline & & 3 & & \\
\hline & & 4 & & \\
\hline & & 5 & & \\
\hline \multirow[t]{4}{*}{5} & Pertanian & 1 & \multirow{4}{*}{-69.75} & \multirow{4}{*}{15.25} \\
\hline & & 2 & & \\
\hline & & 3 & & \\
\hline & & 4 & & \\
\hline \multirow[t]{4}{*}{6} & Perikanan & 1 & \multirow{4}{*}{-70} & \multirow{4}{*}{6.5} \\
\hline & & 2 & & \\
\hline & & 3 & & \\
\hline & & 4 & & \\
\hline \multirow[t]{5}{*}{7} & Kesehatan Masyarakat & 1 & \multirow{5}{*}{-67.4} & \multirow{5}{*}{11.4} \\
\hline & & 2 & & \\
\hline & & 3 & & \\
\hline & & 4 & & \\
\hline & & 5 & & \\
\hline
\end{tabular}




\begin{tabular}{|c|c|c|c|c|}
\hline 8 & Ekonomi dan Bisnis & 1 & \multirow{4}{*}{-32.75} & \multirow{4}{*}{-1.25} \\
\hline & & 2 & & \\
\hline & & 3 & & \\
\hline & & 4 & & \\
\hline 9 & Teknik & 1 & \multirow{4}{*}{-65.25} & \multirow{4}{*}{-8.75} \\
\hline & & 2 & & \\
\hline & & 3 & & \\
\hline & & 4 & & \\
\hline 10 & Teknologi Industri & 1 & \multirow{4}{*}{-68} & \multirow{4}{*}{15.75} \\
\hline & & 2 & & \\
\hline & & 3 & & \\
\hline & & 4 & & \\
\hline 11 & Farmasi & 1 & \multirow{5}{*}{-78.6} & \multirow{5}{*}{6} \\
\hline & & 2 & & \\
\hline & & 3 & & \\
\hline & & 4 & & \\
\hline & & 5 & & \\
\hline
\end{tabular}

Terlihat pada Tabel 6, ada beberapa fakultas signal strength dengan kategori baik di waktu sore yaitu fakultas sastra, hukum, ilmu komputer, agama, pertanian, perikanan, kesehatan masyarakat, teknik dan teknologi informasi. Fakultas yang termasuk kategori signal cukup hanya farmasi dan fakultas ekonomi dan bisnis dengan kategori sangat baik.

Secara keseluruhan kualitas signal strength dan SNR ukhuwahnet pada lingkup kampus 2 universitas muslim indonesia di waktu pagi, sebesar -66,55 dan -7,84 untuk signal strength, diwaktu sore 65,20 dan 0,33 untuk SNR. Kuat sinyal -66,55 dan -65,20 termasuk kategori level baik atau 4 bar sinyal sedangkan nilai SNR -7,84 dan 0,33 termasuk kategori no signal (buruk) atau koneksi sangat tidak stabil, throughput sangat rendah.

\section{Conclusion}

1. Hasil pengamatan signal diwaktu pagi, ada beberapa fakultas signal strength dengan kategori baik di waktu pagi yaitu fakultas sastra, ilmu komputer, agama, pertanian, perikanan, ekonomi, teknik dan teknologi informasi. Fakultas yang termasuk kategori signal buruk hanya farmasi, kategori cukup untuk fakultas hukum dan fakultas kesehatan masyarakat dengan kategori sangat baik

2. Hasil pengamatan signal diwaktu sore, ada beberapa fakultas signal strength dengan kategori baik di waktu sore yaitu fakultas sastra, hukum, ilmu komputer, agama, pertanian, perikanan, kesehatan masyarakat, teknik dan teknologi informasi. Fakultas yang termasuk kategori signal cukup hanya farmasi dan fakultas ekonomi dan bisnis dengan kategori sangat baik.

3. Secara keseluruhan kualitas signal strength dan SNR ukhuwahnet pada lingkup kampus 2 universitas muslim indonesia di waktu pagi-sore, sebesar $-66,55$ dan $-65,20$ untuk signal strength, diwaktu pagi-sore - 7,84 dan 0,33 untuk SNR. Kuat sinyal -66,55 dan -65,20 termasuk kategori level baik atau 4 bar sinyal sedangkan nilai SNR -7,84 dan 0,33 termasuk kategori no signal atau koneksi sangat tidak stabil, throughput sangat rendah.

4. Adapun faktor - faktor penyebab signal to ratio (SNR) memiliki koneksi tidak stabil, sering putus koneksi dan terkadang no signal yaitu pengguna yang melebihi batas kemampuan AP, perangkat AP perlu diupgrade dan tepat menentukan posisi AP, penentuan chanel yang salah dan tidak adanya manajemen bandwith yang baik. 


\section{References}

[1] Satwika. Analisis Coverage Dan Quality Of Service Jaringan Wifi 2,4 Ghz Di Stmik Stikom Indonesia. Jurnal Resistor. Denpasar, (2018)

[2] Sirait Rummi. Optimasi penempatan access point Pada jaringan wi-fi di universitas budi luhur. Jurnal Elektro Vol 4, Jakarta (2012)

[3] Enterprise, Jubilee.100 tip dan trik Wi-fi.Elex Media Komputindo. Jakarta, (2009)

[4] Firdaus, dkk. Penguatan Sinyal Global System For Moile Communication (GSM) Menggunakan Antena Yagi 14 Elemen. Jurnal Elektron Vol 4 No. 2. Politeknik Negeri Padang, (2012)

[5] Center, onno. SNR Margin dan Line Attenuation.

http://onnocenter.or.id/wiki/index.php/SNR_Margin_dan_Line_Attenuation. Agustus, 20, 2019

[6] Sugiyono. Metode penelitian kuantitatif, kualitatif, dan R \& D.alfaeta, bandung, (2010) 